\title{
Disability, gene therapy and eugenics - a challenge to John Harris
}

Solveig Magnus Reindal University of Oslo, Norway

\begin{abstract}
This article challenges the view of disability presented by Harris in his article, "Is gene therapy a form of eugenics?"I It is argued that his definition of disability rests on an individual model of disability, where disability is regarded as a product of biological determinism or "personal tragedy" in the individual. Within disability theory this view is often called "the medical model" and it has been criticised for not being able to deal with the term "disability", but only with impairment. The individual model of disability presupposes a necessary causal link between a certain condition in the individual and disablement. The shortcomings of such a view of disability are stated and it is argued that in order to have an adequate ethical discourse on gene therapy perspectives from disability research need to be taken into consideration.

(Fournal of Medical Ethics 2000;26:89-94)
\end{abstract}

Keywords: Disability theory; gene therapy; eugenics

\section{Introduction}

In the article, "Is gene therapy a form of eugenics?" Harris discusses disability and the production of "fine" children and how this should be achieved. He also criticises people who argue that a predisposition to being impaired will be used as a basis for discrimination against disabled people. Harris builds his critique on what he calls "The moral continuum" and his understanding of disability. He argues that "there is in short no moral difference between attempts to cure dysfunction and attempts to enhance function where the enhancement protects life or health". ${ }^{2} \mathrm{He}$ does not distinguish between gene therapy on the germ line and gene therapy on the somatic line. In his view there is in theory no moral difference between the two practices. Harris does not agree with disabled people who argue that gene therapy is a form of eugenics and that discrimination against them as a group is tantamount to devaluing them as persons. He argues that to decide not to keep a "disabled neonate" alive no more constitutes an attack on the disabled than does curing disability, and that to prefer to remove dis- ability where we can is not to prefer non-disabled individuals as persons. ${ }^{3}$

The wrongs that practising eugenics may involve are, according to Harris: the assumption that those who are genetically weak ${ }^{4}$ should be discouraged from reproducing or are less morally important than other persons, and that compulsory measures to prevent them reproducing might be defensible. But this is not what Harris advocates:

"It is not that the genetically weak should be discouraged from reproducing but that everyone should be discouraged from reproducing children who will be significantly harmed by their genetic constitution. Indeed, gene therapy offers the prospect of enabling the genetically weak to produce and give birth to the genetically strong . . . . It might thus, as we have just noted, enable individuals with genetic defects to be sure of having healthy rather than harmed children and thus liberate them from the terrible dilemma of whether or not to risk having children with genetic defects". 5

Consequently, Harris argues that there is nothing morally wrong per se in practising eugenics, ${ }^{6}$ but that there is a wrong practice. The wrong practice occurs in the moment when a majority, a collective, argues that it is defensible to discourage and/or prevent a minority which is "genetically weak" from reproducing. Thus, morally right eugenics does not deny the "genetically weak" reproduction; it only prohibits or prevents the "genetically weak" from giving birth naturally. Furthermore, according to Harris, it is morally wrong to produce children "who will be significantly harmed by their genetic constitution". In Harris's view eugenics is not wrong and it is a matter of indifference whether we call it eugenics or not: "call it what you will, eugenics or not, we ought to be in favour of it". ${ }^{2}$ In the following I will examine how Harris understands the moral continuum and disability.

\section{The moral continuum}

In arguing for the moral continuum Harris uses a hypothetical example of a woman who has five 
eggs fertilised in vitro, and who wishes to use some of these embryos to become pregnant. Normal practice at an IVF clinic would be to insert two embryos or at most three. Harris asks us to consider the following:

"If preimplantation screening had revealed two of the embryos to possess disabilities of one sort of another, would it be right to implant the two embryos with disability rather than the others? Would it be right to choose the implantation embryos randomly? Could it be defensible for a doctor to override the wishes of the mother and implant the disabled embryos rather than the healthy ones - would we applaud her for so doing?

The answer that I expect to all these rhetorical questions will be obvious. It depends however on accepting that disability is somehow disabling and therefore undesirable".?

Whether this is a moral continuum depends, according to Harris, on accepting that disability is somehow disabling and therefore undesirable. Harris asks us whether it could be defensible for a doctor to override the wishes of the mother and implant the disabled embryos rather than the healthy ones? However, it is not obvious that the mother's wish in all circumstances is what Harris presumes. There could be situations where the mother wished to implant the impaired embryos, or there could be a situation where all the embryos showed signs, at preimplantation screening, of some impairment and the mother still wanted to implant them. Thus, we need to distinguish, on the one hand, whether a mother's or couple's decision is morally justified and, on the other hand, whether the doctor is justified in overriding it. Let us consider the following hypothetical examples.

\section{Achondroplasia}

Example A: A couple, both of whom have the diagnosis achondroplasia, consider having children. As their house and all other facilities, their car and summer cabin, are adjusted to their situation they will have to do major alterations in order to bring up a child of "normal" height. They have only managed to pay some of the costs of these adjustments and cannot see how they can afford to make new alterations in a couple of years. In these circumstances they decide to go to an IVF clinic and ask for a preimplantation screening for achondroplasia. The result of the screening is that three of the five embryos have the gene for achondroplasia. The couple decide they would like to implant the achondroplasia embryos. Is it defensible for a doctor to override the wishes of the couple and implant the embryos without achondroplasia rather than those with achondroplasia?

Example B: A couple with congenital deafness consider having children. For both of them sign language is their first language, because their parents were also deaf. As both speak and lip read the hearing language very poorly they will not be able to communicate with their child through speech. Facilities in the house are adjusted to their situation and most of their friends use sign language. Considering these circumstances they opt for the IVF method of becoming pregnant and as the preimplantation screening shows two embryos of five with the gene for congenital deafness they choose to implant these. Again, is it defensible for a doctor to override the wishes of the couple and implant the three embryos without the gene for congenital deafness?

\section{Underlying presupposition}

Example C: A couple come for a second attempt at in vitro fertilisation. They decide that this will be their final attempt. Last time the woman had a miscarriage. This time a preimplantation screening shows that all the embryos have some sign of impairment. However, the couple want to try to implant the embryos despite supposed impairments and the risk of a miscarriage. Is it defensible for a doctor to override the wishes of the couple and not implant any of the embryos because of presumed impairments?

If Harris considers the offspring of the couples with the diagnoses of achondroplasia and congenital deafness to be examples of "children who will be significantly harmed by their genetic constitution", I suppose he would answer that it is morally wrong to implant the embryos with the impairments under these circumstances and that the parents' decision is not morally justifiable. The right thing to do for the doctor in examples $\mathrm{A}$ and $\mathrm{B}$ would thus be to override the wishes of the two couples, if he or she were convinced that it was morally wrong to produce "children who will be significantly harmed by their genetic constitution". In Harris's terminology the doctor would not be involved in a wrong eugenic practice because he or she is enabling the genetically weak to reproduce and give birth to the genetically strong. However, what about example C, is this couple's wish morally justifiable? I suppose their wish is not justifiable according to Harris if "disability" is undesirable under all circumstances. Again, we might presume that the doctor overrides the couple's wish with reference to the embryos assumed impairments. The underlying presupposition for the doctor's decision might 
have been that even though it is better to produce "unhealthy" children than to produce no children at all this is provided that the "unhealthiness" does not make their lives not worth living. Let us suppose that the doctor views the embryos' "unhealthiness" to be of such a kind that their lives would not be worth living.

After the births couples A and B realise that the doctor has overridden their wishes and decide to sue the doctor on the grounds that she or he has acted negligently in respect of their wishes. The couple in example $\mathrm{C}$ sue the doctor for negligent action and a loss of a potential child. The other two couples charge full economic compensation for the changes that have to be made in order to raise the children, and try to sue the doctor by bringing "wrongful life" cases. However, according to $\mathrm{Heyd}^{8}$ wrongful life cases are at most, victimless crimes:

"And in that respect, even if we cannot, for logical reasons, grant legal standing to the child in its claim for compensation, should not the negligent doctor be held responsible for the wrong and be liable to (criminal) punishment? Putting aside the parents' claim, a wrong was done in the world even if no individual can be identified as its victim". ${ }^{9}$

The problem with these "wrongful life" cases in comparison to other "wrongful life" cases, for instance where "wrongful life" is claimed because of being born with achondroplasia, deafness etc, is that one cannot claim that a wrong was done in the world without acknowledging thereby that "disability" is undesirable under any circumstances. This will also be the case with the couple in example C, where the doctor's overriding decision might have prevented a child being born with, for example, achondroplasia, deafness etc. If the judges follow Harris's view that "disability" is, under any circumstances, undesirable, the couples will not be given any compensation or approval. However, if the judges hold that respect for parental autonomy should be given more weight than preventing the birth of an impaired child, the doctor could be charged for having violated parental autonomy.

Examples $\mathrm{A}, \mathrm{B}$ and $\mathrm{C}$ raise the question of parental autonomy where impairments are stated. The practice of genetic engineering (or treatment) challenges parental autonomy on several levels: first, there is the possibility of resisting genetic engineering, suggested because of supposed "genetic disorders"; second, there is the possibility of agreeing to enhance "genetic disorders" through gene therapy, and third there is the possibility of demanding genetic engineering according to aesthetic standards, intellectual abilities and so forth ("utopian eugenics"). All these examples of how parental autonomy may be exercised raise the issue of normality. While resisting genetic engineering (or treatment) suggests a widening of diversities, the exercise of parental autonomy in relation to genetic engineering of "genetic disorders"and "utopian eugenics" increases tendencies to adopt narrow notions of normality and can provide opportunities to stigmatise and exclude people. This is what disabled people fear will be the result of genetic technology.

In Harris's thinking there is a presupposition that "disability" is undesirable under any circumstances, otherwise there would be no motive to try to cure or obviate "disability" in health care more generally. ${ }^{7}$ The crucial question to be asked then is what is "disability"?

\section{What is disability?}

Harris argues that we know pretty clearly what we mean by disability. According to him, a disability is a physical or mental condition we have a strong preference not to be in ourselves. What is more important, he argues that it is a condition,which is in some sense a "harmed condition". ${ }^{10}$ According to Harris, a disability or incapacity is disabling in some sense, and it is a harm to those who suffer it. The "harmed condition" can be a result of someone knowingly disabling another individual or leaving the individual disabled when the disability could be removed. ${ }^{11}$ An example of knowingly disabling an individual is provided, according to Harris, by the case of a pregnant woman who knows that something will have a bad effect on her fetus, knows she could remove the bad effect by a simple dietary adjustment, and who fails to make that adjustment.

Harris further defines disability as a disabling condition relative to active and passive intervention, that is, he defines disability as a function of people's choices caused by an action or refraining from an action. It is a condition within the individual caused by earlier choices made by parents or professionals before, during or after pregnancy. Harris argues that his definition avoids certain obvious pitfalls: "First it does not define disability in terms of any conception of normalcy. Secondly it does not depend on post hoc ratification by the subject of the condition - it is not a prediction about how the subject of the condition will feel". ${ }^{11}$ The second element is especially important for Harris as his definition can thus be used for the potentially self-conscious: gametes, embryos, fetuses and neonates and for people who are temporarily unconscious; it is a definition 
which does not wait upon subsequent ratification by the person concerned.

However, one pitfall Harris does not avoid is to regard disability as an individual problem, a condition within the subject. This understanding of disability is, within contemporary disability studies, familiar as the medical model, where disability is seen as a product of biological determinism or personal tragedy. This individual, or medical, model sees disablement as a medical problem, which affects only a small proportion of the population. Recent studies in Britain, however, conclude that four out of every ten adult women and men have a longstanding illness or disability. Other studies show that internationally there are around 50 million disabled people in Europe and approximately 500 million worldwide. ${ }^{12}$ Disability is far from merely being a medical problem that can be "cured", on the contrary it is mainly a cultural and sociopolitical problem. The medical notion of disability, seeing disability as a cause of a limitation within the individual, cannot account for the fact that not all people with losses, diseases, illnesses etc experience disablement. If it were that impairment, some functional difficulties of any kind, were tantamount to identifying someone as a disabled person then the medical notion of disability would have to be utterly comprehensive, exhaustive, in order to account for an understanding of what disability is.

\section{Research studies}

A comparison of three research studies carried out in Norway showed that the number of disabled people decreased when a commonsense definition of disability was used as a starting point. When the definition of disability was based on self-report and common sense, the estimate of disabled people was 15 per cent. However, when criteria-based definitions were the starting point, 35 and 40-50 per cent of the population were categorised as disabled. ${ }^{13}$ These people were considered disabled because of certain impairments. If the medical notion of disability is correct, stating disability as a condition within the subject, which is disabling in some sense, then having impairments and the experience of disablement, should coalesce. In Harris's definition of disability "how the subject of the condition will feel" is left out. Harris leaves it out because decisions about whether individuals will come into existence have to be taken before we can know how they will feel and therefore we have to decide on some "objective" basis. However, as shown above the issue of identity is a challenge to definitions that adhere to a purely medical perspective of disability.
Although Harris regards the cause of disability as relative to active or passive intervention, his understanding of disability comprises a causal link between having a certain condition in the individual and being disabled. Hence, anatomy is seen as destiny. As already mentioned, disability studies show that there is a distinction between having an impairment and being disabled. Because of this distinction, researchers have argued for a division between a certain condition in the individual and disablement. ${ }^{14}$

To deny that there is a necessary causal link between a certain condition in the individual and disablement does not imply that researchers defending a social model deny that there are such things as impairments. On the contrary, impairment simply means that aspects of a person's body do not function or they function with difficulty. ${ }^{15}$ What they insist on is that whether an impairment results in disablement is conditional on other things than merely the impairment itself. They acknowledge the fact that individuals might regard their impairment as positive, neutral or negative, and that this might differ according to time and place. Hence, they favour a social model of disability where the basis of disability is located in social conditions.

Advocates for the social model maintain that disability is a sociopolitical construction, a product of organisation and culture rather than a personal limitation due to a person's impairment, where agency and structure are intricately knit together. Such a view implies that social barriers, norms and values, rather than impairments, should be analysed in determining quality of life. Debates in genethics on quality of life often rest on an individual model of disability, hence low quality of life is attributed to an impairment of some kind and associated with "personal tragedy". However, it is not unusual for disabled people to report that their lives have changed for the better following disablement. ${ }^{16}$ Of course the social models do not deny that impairments can affect quality of life but they deny a priori assumptions, on which, for example, the practice of fetal screening for abortion and infanticide for babies with significant impairments, rests.

\section{'Curing disability' and discrimination}

The main discrimination that results from the creation and construction of disability is that various institutions refuse to give up individual models of disability. The very idea of "curing" disability is the core element in the discrimination of disabled people because the "curing ideal" resides in conformity and normalcy. The presupposition of the "curing" ideal makes the removal of disad- 
vantage contingent upon the removal or "overcoming" of impairment: in other words, full participation in society is found through cure or fortitude. ${ }^{17}$ To challenge the unacceptable features of the medical model does not imply that disabled people do not need, or see, at specific points in their lives, the necessity of medical support. However, what is being challenged are the social conditions and relations in which such encounters take place, the enveloping of disabled people's identity in medical terms. It is important that their voices are heard and that they have much more effective participation in decisions which affect them. ${ }^{18} \mathrm{~A}$ consequence of the medical model, in that it deals only with impairment, is that resources are directed into impairment-related research and intervention, whereas scant resources are channelled into social change for the inclusion of people with impairments. Cornes ${ }^{19}$ found that in relation to impairment new technology is widespread, well established and well funded compared with technology that could lessen disabling barriers. Another example is research within gene therapy that strives to "cure disability", while ignoring the social and cultural factors that make not walking, hearing, seeing etc into a problem. There is little public questioning of the distribution of the funds between these two approaches. The main reason this has not been an issue for discussion is the persistence of an individual model of disability in the culture and the social structures. Advocates for the "curing" ideal will argue that we cannot assume that society is obliged to undertake changing the world for disabled people so as to render them not disabled in all cases, rather than eliminating the impairment, especially where doing that is cheaper. ${ }^{20}$ Such a view rests on the assumption that impairments are primarily a result of genetic predisposition and biological determinism. Thus, impairments can be avoided and eliminated through abortion, sterilisation, and infanticide or cured through somatic and germ line therapy. This view underestimates the prevalence of disablement, which is increasing, especially in wealthier, developed societies due to a combination of an aging population and medical interventions which prolong life. Research in Britain showed that four per cent of those aged 16-64 suffered from some impairment compared to $28 \%$ of the population over the age of $65 .{ }^{21}$ The insistence on individual models of disability within social structures means seeing the "impairment" exclusively as the problem and will render the aging population ever more disabled as the principle behind service provision will continue to neglect disabling barriers. Approaches of the individual model to the study of aging have been criticised for failing to take account of external and structural factors, which influence people's experience of aging. ${ }^{22}$ Another aspect such a view disregards is the creating of impairments through physical abuse, industrial accidents, unsafe environments, environmental pollution, stress and exhaustion, war and violence. ${ }^{23}$

To continue to persist with individual models of disability, equating the problem of disability to impairments and individual conditions, is itself a discrimination against disabled people. Historically, the right to define has been an instrument of power in relation to minority groups and in the oppression of, and discrimination against, people. Conceivably, it is not a coincidence that the majority of non-disabled people use an individual model of disability, whereas disabled researchers use a social model of disability. Non-disabled people's insistence on the right to define who is disabled or what disability is, would in itself constitute discrimination against disabled people if the understanding that disabled people themselves have of disability is ignored in, for instance, academic discussions.

Let us now return to Harris's position. If it is correct that Harris's definition of disability stems from an individual view of disability, then his argument for claiming that gene therapy is not a form of eugenics and discrimination against the disabled as a group, would also rest on this presupposition. If discussions on gene therapy use individual models of disability, dominated by biological understandings as a point of departure, disabled people will experience these discussions as eugenics in disguise and hence as discrimination against them. This is because biological determinist understandings were the underlying presupposition in the eugenic policies that, for example, were at the root of sterilisation laws introduced in several countries in the $1930 \mathrm{~s}^{24}$ Accordingly, in order to have a sincere ethical debate on gene therapy comprehension demands not just biology and rational reasoning but the methodologies of the social sciences as well. Hence, the perspectives and empirical evidence gained from disability studies should eventually be considered and not ignored in philosophical research into bioethics.

\section{Conclusion}

Individual models of disability and especially the "medical model" are inadequate as models for explaining the phenomenon of disability. They adhere to a causal understanding of the interplay between impairment and disablement. As long as ethical thinking within gene therapy adheres to a 
"medical model" of disability, individual differences as impairments will be regarded as essential attributes which are given moral status. The medical model of disability leads to value judgments by the unimpaired in so far as they view an impairment as meaning that a person has such poor quality of life that that life is judged, by the unimpaired, to be not worth living. These erroneous judgments will only be avoided if social models of disability are taken into account and the views of individuals with those impairments are sought and heard.

Solveig Magnus Reindal, PhD, is a Research Fellow in the Department of Special Education, University of Oslo, Norway. Her research interests are in the philosophy of special needs education.

\section{References and notes}

1 Harris J. Is gene therapy a form of eugenics? Bioethics 1993;7:178-87.

2 See reference $1: 184$

3 See reference $1: 182$.

4 The term "genetically weak" is not Harris's own term. Harris

The term "genetically weak" is not Harris's own term. Harris
uses this term to echo the words of Ruth Chadwick. He takes uses this term to echo the words of Ruth Chadwick. He takes
genetically weak to refer to "those possessing a debilitating genetically weak to refer to "those possessing a debilitating
genetic condition or those who will inevitably pass on such a genetic condition or those who

5 See reference $1: 183$.

6 Harris believes that gene therapy is in principle ethically sound except for its possible connection with eugenics. He argues that the nub of the problem turns on how we are to understand th objective of producing "fine children". See reference 1:178.
7 See reference 1:179

8 Heyd D. Genethics: moral issues in the creation of people. London: University of California Press, 1992.

9 See reference 8:36.

10 See reference $1: 180$.

11 See reference

12 Barnes C, Mercer G. Exploring the divide: illness and disability. Leeds: The Disability Press, 1996:1.

13 Byggforsk, Norges byggforskningsinstitutt. Begrepet "funksjonshemmet". En diskusjon. Prosjektrapport 1993;108:26.

14 Oliver M. Defining impairment and disability: issues at stake. See reference 12: 39-55.

15 Crow L. Including all of our lives: renewing the social model of disability. See reference 12: 55-74.

16 Finkelstein V, French S. Towards a psychology of disability. In: Swain J, Finkelstein V, French S, Oliver M, eds. Disabling barriers: enabling environments. London: Open University Press/ barriers: enabling environ

17 See reference 15:57.

18 See Barton L. Sociology and disability: some emerging issues. In Barton L, ed. Disability E society: emerging issues and insights. London: Longman, 1996:3-18.

19 Cornes P. Impairment, disability, handicap and new technology. In Oliver M, ed. Social work: disabled people and disabling environments. London: Jessica Kingsley Publishers, 1991: environment.

20 Buchanan A. Choosing who will be disabled: genetic intervention and the morality of inclusion. Social Philosophy \& Policy 1996;13:18-46.

21 Bury M. Defining and researching disability: challenges and responses. See reference 12:17-39.

22 Zarb G. The dual experience of aging with a disability. See reference 16: 186-197.

23 Abberley P. Work, Utopia and impairment. See reference 18: 61-83; Beresford P. Poverty and disabled people: challenging dominant debates and policies. Disability \& Society 1996;11: 553-67.

24 Broberg G, Roll-Hansen N, eds. Eugenics and the welfare state: sterilization policy in Denmark, Sweden, Norway, and Finland. East Lansing/Michigan: Michigan State University Press, 1996.

\section{News and notes \\ Eighth International Congress on Ethics in Medicine}

The Eighth International Congress on Ethics in Medicine will be held on November 5 - 9, 2000 in Beer Sheva, Israel. The congress is being co-sponsored by Ben Gurion University of the Negev (Beer Sheva, Israel); Beth Israel Medical Center (New York); the Center for Jewish Medical Heritage (Tel Aviv); the British Institute of Medical Ethics (London), and the Karolinska Institute (Stockholm). The central theme, Ethics
Across Cultures, Eras and Borders, will be discussed by medical personnel, ethicists and scholars from around the world.

Abstract submission deadline: May 312000.

For further information please contact: Ethics Congress, Peltours-Te'um Congress Organisers, POB 52407, Jerusalem 91520, Israel; tel: 9722648 1245; fax: 9722648 1305; email: teumcong@netmedia.net.il 